\title{
Collaborative Integration of Bioinformatics Knowledge Management System and Mobile Wireless Devices
}

\author{
Fahad Omar Alomary \\ Al-Imam Mohammad Ibn Saud Islamic University (IMSIU) \\ The Executive Director of Center of Cyber Crimes Studies \\ College of Computer and Information Sciences (CCIS) \\ Riyadh, Kingdom of Saudi Arabia \\ Fahd.alomary@gmail.com
}

\begin{abstract}
Knowledge Management System (KMS) currently becomes a common medium to distribute knowledge by using the Information Technology (IT) as enabler tools for everyone to reach, share with among the members, and used it from any workplace in the world at any time. In the context of bioinformatics community of practice (COP) is also has opportunities to leverage and share their knowledge with collaborative technology to create, gather, access, organize, distribute and disseminate the knowledge among them for various purposes such as learning process, research and development (R\&D) and others. This paper describes on the theoretical concepts and approach of integrating mobile wireless devices into Bioinformatics KMS that could be implemented in institution by demonstrating on how the framework of KMS model that is developed using relevance software. The achievement of conducting mobile wireless devices into Bioinformatics KMS framework is an added value for the CoP in the institution that needs to implement the Bioinformatics KMS, which can help them to achieve their aims and mission statements. The emphasis also will be given to the activities for each stage in the KM life cycle including the critical success factor (CSF) in order to make sure that Bioinformatics KMS initiatives will deliver competitive advantage to the CoP in the institutions.
\end{abstract}

Keywords: Community of Practice, Knowledge Management, Knowledge Management System, Mobile Device, Collaborative Technology, Critical Success Factor, and Bioinformatics.

\section{Introduction}

Knowledge Management (KM) has been a buzzword in a range of subject disciplines for many years, and has latterly been applied to higher learning institution. With the growth of this concept, there has also been a need to develop ways of understanding knowledge processes within this domain and to select KM systems that can help in knowledge creation, storage and sharing. In terms of definition, KM is the systematic, explicit, and deliberate building, renewal, and application of knowledge to maximize an enterprise's knowledge-related effectiveness and returns from its knowledge assets [1].

$\mathrm{KM}$ is a discipline that provides strategy, process and technology to share and leverage information and expertise that will increase our level of understanding to more effectively solve problems and make decision [2]. The objectives of knowledge management are to make the organization act as intelligently 
as possible to be secured in term of viability and overall process, and to realize the best value of its knowledge assets.

A bioinformatics institution seems to be by its nature especially the suitability for applying the system in KM principles and methodology [2]. The main reasons are, the institution usually possess a modern biological information infrastructure, its knowledge of the community as well as the biologists who generally love to share their knowledge with others. The communities are also desire to acquire knowledge from accessible sources as fast as they could. Therefore, in the bioinformatics industry, KM can be defined as a systematic process that creates, captures, shares, and analyzes knowledge in ways that directly improve performance.

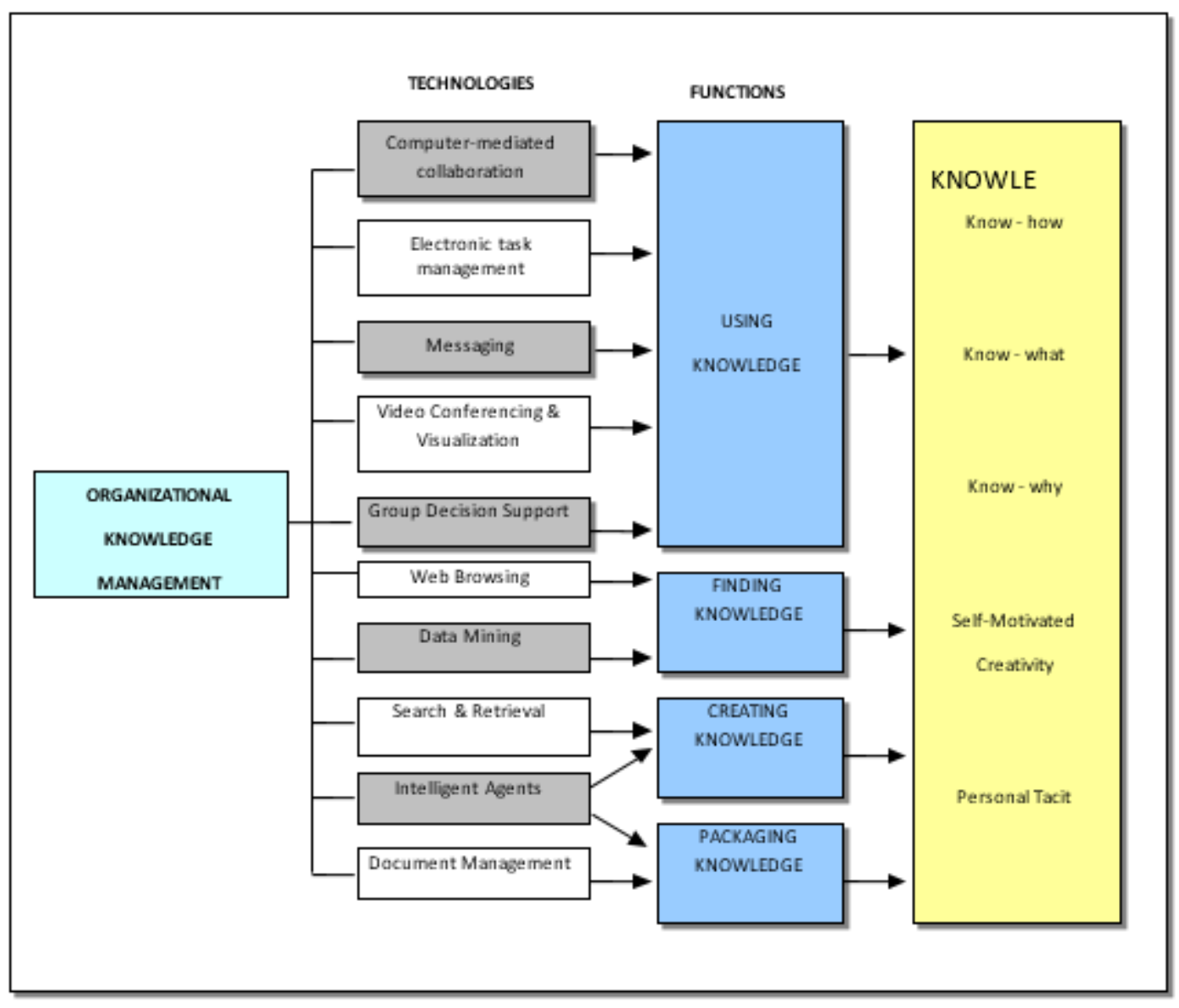

Figure 1. The Technical Perspective of a Knowledge Management System

From a theoretical standpoint, Knowledge Management Systems (KMS) refer to the information systems adopted and designed which efficiently and effectively leverage the collective experience and knowledge of employees to support information processing needs as well as enabling and facilitating sense making activities of knowledge workers [4]. KMS can include of any type of information, including both quantitative and qualitative. Qualitative information may be in the structured or semi structured text format and often takes the form of reports from prior project leaders on what they have learned during the project. Figure 1 simplifies the technical aspect of a KMS [5]. A well-designed of KMS should consider and concern about these four core features so that the system will bring a lot of benefits to the organization. The four core features are: 
Fahad Omar Alomary; Collaborative Integration of Bioinformatics Knowledge Management System and Mobile Wireless Devices, Transactions on Machine Learning and Artificial Intelligence, Volume 7 No 2 April, (2019); pp:

- Infrastructure, Content and Portal

- Collaboration and Learning

- Social Capital and Expertise

- Communities, Business Intelligence and Integration

The development of KMS involved a number of technologies. The combination of these technologies will produce a system that can collect, sort, store, and share the knowledge throughout the institution. These technologies can be categories as follow:

- Intranets - secure internal networks, to provide an ideal environment for sharing information accessed using a standard browser.

- Information Retrieval Engines - search engines are an absolute necessity and are the integral part of KMS.

- Groupware - facilitate information sharing via e-mail, online discussions, databases and related tools. Its collaborative features can result in the creation of stores of untapped knowledge.

- Database Management Systems - computer databases are common repositories of information. KMS can be constructed to incorporate the information that is stored in the organization and accessible by all.

- Data Warehousing and Data Mining - data warehouses are centralized repositories of information. Data mining refers to specialized tools that allow the organization to convert increasingly complex sets of data into useful information.

- Document Management System - a collection of tools that facilitate electronic document management, including storage, cataloguing, search, analysis and routing.

- $\quad$ Push Technologies - delivering of appropriate information to individual based on specific criteria.

- Collaboration - expert modelling and decision making analysis that lead to more collaboration, information expertise and insight sharing among knowledge workers.

- Visualization and Navigation System- relationship between knowledge elements and holders of knowledge.

\section{Theoretical Aspect of Km and Mobile Computing}

There are six theoretical aspects that will be discussed in this paper and they are framework, technology, process, development, life cycle, and people.

\subsection{Knowledge Management Framework and Technology}

There are ten KM frameworks that have been identified. Table 1 summarizes and compares these frameworks. KMS is also defined as the collection of technologies that can collect, sort, store, and share the knowledge throughout the organization. Based on that definition, the technologies that can be used in the development of KMS are:

- Intranets - secure internal networks, to provide an ideal environment for sharing information accessed using a standard browser.

- Information Retrieval Engines - search engines are an absolute necessity and are the integral part of KMS. 
- Groupware - to facilitates information sharing via e-mail, online discussions, databases and related tools. Its collaborative features can result in the creation of stores of untapped knowledge.

- Database Management Systems - computer databases are common repositories of information. KMS can be constructed to incorporate the information that is stored in the organization and accessible by all.

- Data Warehousing and Data Mining - data warehouses are centralized repositories of information. Data mining refers to specialized tools that allow the organization to convert increasingly complex sets of data into useful information.

- Document Management System - a collection of tools that facilitate electronic document management, including storage, cataloguing, search, analysis and routing.

- $\quad$ Push Technologies - delivering of appropriate knowledge to individual based on specific criteria.

- Collaboration - expert modelling and decision make analysis that lead to more collaboration, information expertise and insight sharing among knowledge workers.

- Visualization and Navigation System- relationship between knowledge elements and holders of knowledge.

Table 1: Comparative Summary of the Descriptive Framework (Adapted from [6])

\begin{tabular}{|c|c|c|c|}
\hline -Dimensions & Focus & Roots/ & Knowledge Resources \\
\hline Authors & & & \\
\hline [1] & $\begin{array}{l}\text { Identify management influences on the conduct of } \\
\qquad \mathrm{KM}\end{array}$ & Not indicated & \\
\hline [7] & $\begin{array}{c}\text { Manage interaction between organization's } \\
\text { technological capabilities and knowledge development } \\
\text { activities }\end{array}$ & Field research & $\begin{array}{l}\text { - Emplayee knawledge } \\
\text { - Knowledge embedded in } \\
\text { physical systems }\end{array}$ \\
\hline [8] & $\begin{array}{l}\text { Pride a basis for benchmarking the conduct of KM } \\
\text { within and between organization }\end{array}$ & $\begin{array}{l}\text { Consulting } \\
\text { experiences }\end{array}$ & \\
\hline [9] & Describe the working of knowing organization & $\begin{array}{l}\text { Synthesis of past } \\
\text { research }\end{array}$ & \\
\hline [10] & $\begin{array}{l}\text { Characterize a conceptualize-reflect-act-retrospect } \\
\text { cycle for governing the conduct of KM }\end{array}$ & Not indicated & \\
\hline [11] & $\begin{array}{l}\text { Identify barriers to transferring best practices within } \\
\text { an organization }\end{array}$ & $\begin{array}{l}\text { Synthesis of past } \\
\text { research and } \\
\text { empirical study }\end{array}$ & \\
\hline [12] & Characterize and measure intellectual capital & $\begin{array}{c}\text { Practical } \\
\text { organizational } \\
\text { experiences }\end{array}$ & $\begin{array}{l}\text { - Human capital } \\
\text { - Organizational capital } \\
\text { - Customer capital }\end{array}$ \\
\hline [13] & $\begin{array}{l}\text { Characterize knowledge creation through } \\
\text { interaction of tacit \& explicit knowledge and among } \\
\text { individual, group and organizational entities }\end{array}$ & Not indicated & \\
\hline [14] & $\begin{array}{l}\text { Using technology to accomplish KM at KPMG } \\
\text { Peat Marwick }\end{array}$ & Case study & \\
\hline
\end{tabular}

\subsection{Knowledge Management Process}

Knowledge management (KM) processes comprise of knowledge creation, knowledge storage, knowledge distribution and knowledge application, as illustrated in Figure 2. The act of creating knowledge coincides with the act of working through the learning spiral of conceiving, acting and reflecting. Reflection is key to knowledge creation. Companies must develop the infrastructure to capture, store and disseminate the knowledge created from experience. KM allows organizations to leverage lessons learned to be more effective in the future. In addition, a KM system must help users to get their work done easier and more efficiently. 
Fahad Omar Alomary; Collaborative Integration of Bioinformatics Knowledge Management System and Mobile Wireless Devices, Transactions on Machine Learning and Artificial Intelligence, Volume 7 No 2 April, (2019); pp:

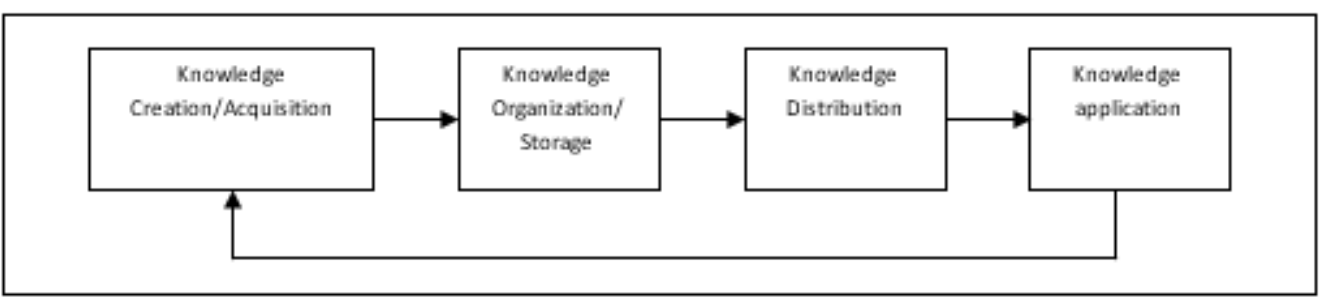

Figure 2. Knowledge Management Process

\subsection{Knowledge Management Development}

KM development involves four steps [15]:

- Determine the organization's knowledge needs. The aim of this step is to determine the core competencies or focused knowledge needs of the organization [16]. The knowledge needs, are driven by the nature of the business the organization is in and desires to be in.

- At an organizational level, the knowledge needs are a function of the organization's products and services and the processes by which the products are produced. At an individual level, the knowledge needs are a function of the things a worker is responsible and accountable for and the decision to be made and actions to be taken.

- $\quad$ Determine the current state of organizational knowledge base or memory. The aim of this step is to determine where and how the organization's current knowledge is assimilated and disseminated. Using the previously identify knowledge needs, the existing sources of knowledge or organizational memory are identified and evaluated for the ease of use and ability to provide accurate, relevant, and timely knowledge.

- $\quad$ Determine the gaps in knowledge and barriers to organizational learning. The aim of this step is to determine why the organization is not creating and applying knowledge that is accurate, timely and relevant. The output of this step is a list of improvement opportunities for the organization learning process.

- Develop, implement and improve proactive "KM strategies" to support organizational learning. The aim of this step is to develop proactive strategies to support the creation, assimilation, dissemination, and application of the organization's knowledge.

\subsection{Knowledge Management Life Cycle}

Knowledge management cycle consists of five phases as what [17] propose in order to support community of practice. The detail discussion is as follow;

- $\quad$ Originate/create knowledge - members of an organization develop knowledge through learning, problem solving, innovation, creativity, and importation from outside sources.

- $\quad$ Capture/acquire knowledge - members acquire and capture information about knowledge in the explicit forms.

- $\quad$ Transform/organize knowledge - in written material and knowledge bases.

- Deploy/access knowledge - organizations distribute through education, training program, and automated knowledge base system or expert networks.

- $\quad$ Apply knowledge - KM aims to make knowledge available whenever it is needed. 
Based on the literature reviewed on KM $[7,13,18,19,20,21]$, the consolidation of the research has derived a KM lifecycle as shown in Figure 3. This KM life cycle is depicted in the simplified way, as it suggests a strict sequence of identifying, creating, transferring, storing, (re)-using, and unlearning language [22].

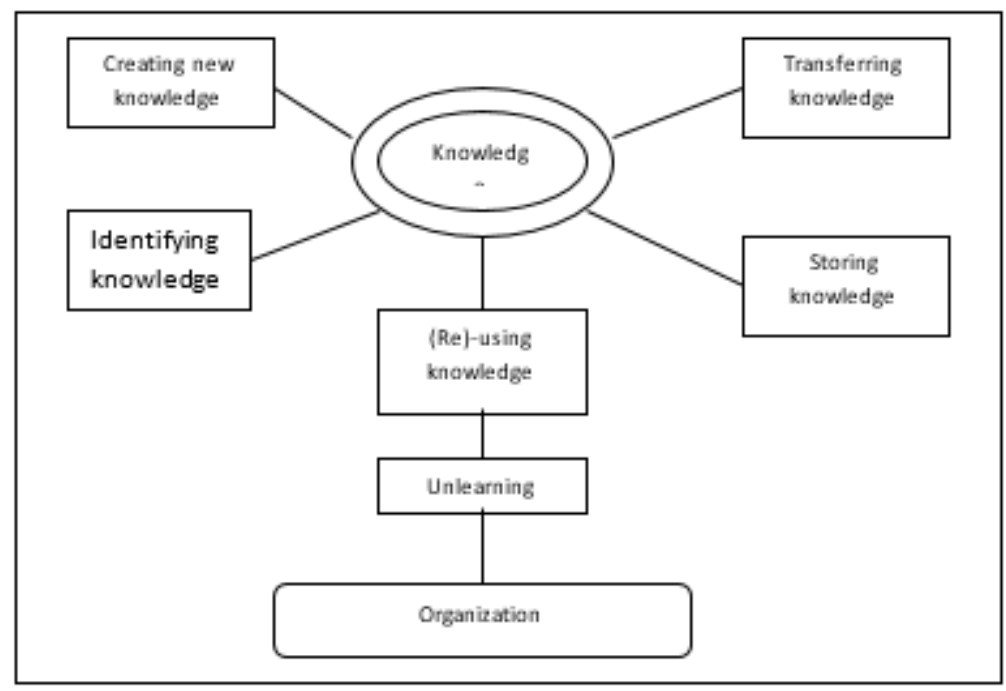

Figure 3. The Knowledge Management Life Cycle

\subsection{Knowledge Management and Community of Practice in the Bioinformatics' Institution}

Knowledge won't be well managed until some groups within a firm have clear responsibility for the job. Among the tasks that such a group might perform are collecting and categorizing knowledge, establishing a knowledge-oriented technology infrastructure, and monitoring the use of knowledge.

A task group will comprise of chief knowledge officer (CKO), Staff or Researcher Officer (RO) who are working in a particular purpose, Chief Information Officer $(\mathrm{ClO})$ who are working for developing and maintenance the system, Chief Task Officer (СТО), the program manager, and the chief knowledge architect (CKA) [3].

\subsection{Knowledge Management and Mobile Computing}

Mobile computing environment allows a group of individual or CoP to work together on a task for common objectives of business when all the individuals have computers connected to a network with wired or wireless that allows them to do their work such as send e-mail to one another, share data files and schedule meetings. From the wireless devices and technology, CoP can easily manage and perform their works for a particular mission at anytime and anywhere.

\section{A Case Study of Integrating Mobile Wireless Devices into Bioinformatics KMS Implementation}

There are three basic possibilities of how the bioinformatics institutions could be exploited the KM ideas and principles. Firstly, is the management of knowledge in term of farmers' success stories and others that related with the farmers' experiences. Secondly is how to manage knowledge for decision support, to improve the internal document management and exploitation, to increase the level of information and 
Fahad Omar Alomary; Collaborative Integration of Bioinformatics Knowledge Management System and Mobile Wireless Devices, Transactions on Machine Learning and Artificial Intelligence, Volume 7 No 2 April, (2019); pp:

34-45

knowledge dissemination. Lastly is how to make use the qualitative of change in the educational process itself. Generally, collaboration in bioinformatics institution could involve the following people.

- Academician in bioinformatics - their roles are as teachers and become designers of learning experiences, processes, and environments. They concerned with identifying and then transmitting intellectual content and more focused on inspiring, motivating, and managing an active learning process for students.

- $\quad$ Researchers - process or generate new ideas by doing research.

- Administrators - manage all aspects of the bioinformatics institution tasks such as financial management, security, students' registration and others.

- Biologist - study, accept, and review the knowledge in bioinformatics institution.

- $\quad$ Sponsors - the agent who sponsors the students or researchers in completing their studies or research works.

In this context, they are working together, hand in-hand, in their institution to achieve their aims and missions. In this case, there are also has three important components of the KMS implementation in bioinformatics institution. The components are to serve the community, staff, and administration of the bioinformatics institution. Below is some description about the goal:

\subsection{Community}

One of the most important objectives is to support and encourage interaction between the bioinformatics institution and local community. Both individuals and community-based organizations may want to investigate an issue, drawing upon the expertise of bioinformatics institution faculty and staff. Bioinformatics institution involvement includes diverse activities such as public presentations, guidance, research projects, and educational outreach. The use of the Internet is an obvious deployment strategy for the community and any underlying database design should support intuitive browsing and topic-based search capabilities. In fact, the Internet can extend the notion of "local" community to include a geographically dispersed intellectual community interested in the research and educational materials generated by bioinformatics institution.

\subsection{Staff / Researcher / Biologist}

Bioinformatics institutions' staff has somewhat different set of objectives. The bioinformatics institution is developing its research presence through graduate education, grants and funding, technology transfer, and scholarly publications. In a very real sense, this mirrors some of the requirements that face organizations such as consulting companies and industrial research laboratories. How can the bioinformatics institution researchers find collaborators, facilities, and grant proposals that might support new projects. The Internet is allowing professional societies and other academic institutions to build online intellectual communities.

\subsection{Administration}

From an administrative perspective, the bioinformatics institution would like to promote community involvement and research activity. While these activities are not completely aligned, a KMS could enable key administrators to gain insights with regard to ongoing activities. Administrative capabilities should support the development of policies that encourage new projects and activities in line with the strategic 
directions set for the university. For example, community contacts and project outcomes could be collected and used to foster new community outreach initiatives.

The need to develop and maintain a KMS is common to many knowledge-intensive organizations. While the term "KM" has become overloaded with different meanings, there is a need to develop specific strategies to capture and organize knowledge assets or expertise. Bioinformatics institution is a knowledge-intensive organization that could benefit from KM efforts.

There are seven steps of critical success factors (CSF) to KM process in the bioinformatics institutions. The steps are:

- $\quad$ The identify stage determines which core competencies are important to academic success. Every department needs robust knowledge about its pedagogical needs and expectations from its members, services and administration. An understanding needs to be developed to settle its place in the pedagogical world and in other organizational and environmental aspects such as research endeavors and consulting services offered by the department.

- The collect stage deals with acquiring the internal and external knowledge, educational skills, fundamental theories and human experience needed to create the selected core responsibilities and knowledge domains.

- $\quad$ The select stage takes the continuous stream of collected, formalized knowledge and assesses its value. Initially, one framework should be selected as the basis for organizing and classifying knowledge to be stored in the Knowledge Bank or Repositories.

- Departmental memory resides in three different forms: in human minds, on paper and electronically. The store stage takes the nuggets of knowledge and classifies them and adds them to the departmental memory. Much of this knowledge can be represented in electronic form as expert systems. This is where even tacit, intangible knowledge assets are transformed to tangible one.

- $\quad$ The share stage retrieves knowledge from the departmental memory and makes it accessible to the users. Individuals, teams and departments often share ideas, opinions, gossip, knowledge \& expertise in meetings held in person or through groupware.

- The apply stage reclaims and uses the needed knowledge in performing tasks, solving problems, making decisions, researching ideas and learning. To reclaim just the knowledge, requires that the system understand the user's purpose and context. To receive the knowledge at the right time requires a proactive system that monitors the user's actions and behavior and determines his/her purpose.

- The create stage uncovers new knowledge through many avenues, such as observing students, student feedback and analysis, research, experimentation, creative thinking and automated knowledge discovery and data mining.

- The features and a model of system configuration of KMS are as shown in Figure 5. Among these functionalities at the bioinformatics institution is:

- Electronic on-line document sharing including sharing of files, workflow diagrams, tools, procedures, manuals, best practices, and lessons learned etc. It is how students, lecturers, 
Fahad Omar Alomary; Collaborative Integration of Bioinformatics Knowledge Management System and Mobile Wireless Devices, Transactions on Machine Learning and Artificial Intelligence, Volume 7 No 2 April, (2019); pp:

administrators, researchers and sponsors in the communities can share the ideas or communicate the new knowledge, learn and then use it effectively.

- Correspondence Handling and Tracking System (CHATS) for the management of all correspondence, complaints, enquires etc. Here, students can communicate with their lecturers or sponsors regarding their studies or financial problem and other matters without having to arrange for the meeting and have to wait for a long time to see face to face. Students also can discuss with each other synchronously, and they can grab the result of their discussion as fast as can.

- Extensive collaboration tools such as group and individual calendars, task and resource management, "to-do" lists, emails, discussion boards, and on-line surveys. It is really important for the people in the bioinformatics institution to plan, manage and collaborate with each other. As for example, with the discussion board, the administrators can discuss with the biologists about the structuring of the any related of fields, and others.

- Various security features to ensure that information is only available to the people who need it. The password and login are only for the authenticated person in the bioinformatics institution. Only those people who have the password can access the databases or the information, such as only the students who registered or in the class of certain lecturer are available and authenticated to access the lecturers' databases and websites.

- Information retrieval through Search and Advanced Search to allow users to find information in an easy and simple way. Here, we can see that most of the bioinformatics institutions have their own websites and that are facilitated with searching tools. By typing words to be searched in the searching box, it will display the information that is needed. It is useful for the students and researchers especially in completing their tasks.

- $\quad$ Flexible views so that each user can tailor the portal to meet their own requirements

- Easily implemented within a company or community due to its Internet architecture. Bioinformatics institution nowadays has their intranet and can link to other information and institutions via the intranet. KM system that will be implemented must make sure that it can link to others.

\section{Results and Discussion}

Bioinformatics institutions do have a significant level of KM activities, and it is important to recognize these, and use them as foundations for further development, rather than to invent a whole new paradigm. CoP must recognize and respond to their changing role in a knowledge-based society. In order to assess the challenges of bioinformatics institutions face in embedding KM, we use Davenport's four types of KM objectives as lens through which to view bioinformatics institutions: the creation and maintenance of knowledge repositories; improving knowledge access; enhancing knowledge environment; and, valuing knowledge.

The Bioinformatics KM system in the CoP institution, need its own suitable framework. The current frameworks are not suitable to the CoP institution because they do not emphasis on the role of human, technologies and the content development itself [23]. Bioinformatics institution consists of human who managing it, administrating, doing research, and doing teaching and studying; consists of the technologies which are needed by the human to convey and distribute their content which are ideas and knowledge. 
It is consists of the content development, which is the KM process. The proposed model of Bioinformatics KM framework for the communities is shown in Figure 4. In this case, a prototype system by using $A$ relevance software has been developed. This figure shows the role of technologies in order to acquire and disseminate knowledge in the CoP. In this case, the system set up was based on bioinformatics CoP in a selected university in Saudi Arabia. As a general concept or overview of KMS functionality as well its components in bioinformatics environment, it could be viewed as shown in Figure 4 and Figure 5. This KMS development takes the consideration and based on the technical perspectives as stated in the literature review section. Especially that was related to technologies, its functionality and the knowledge (tacit and explicit) or content development and as well as its implementation.

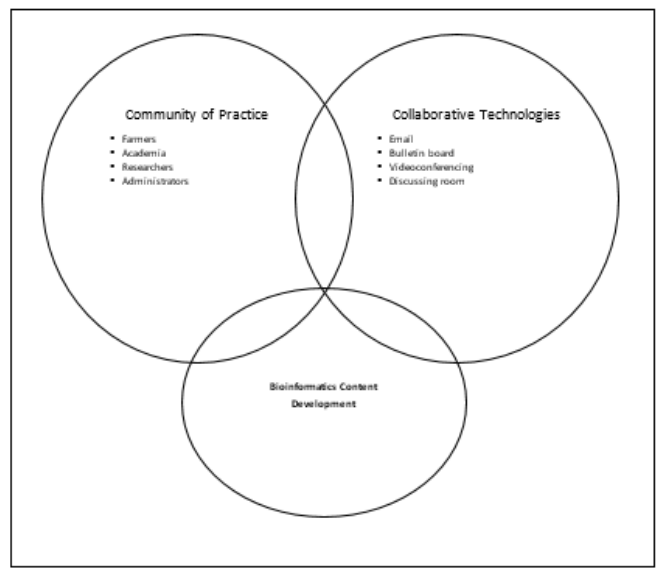

Figure 4. The Components of Bioinformatics Knowledge Management System Framework in Collaborative Environment

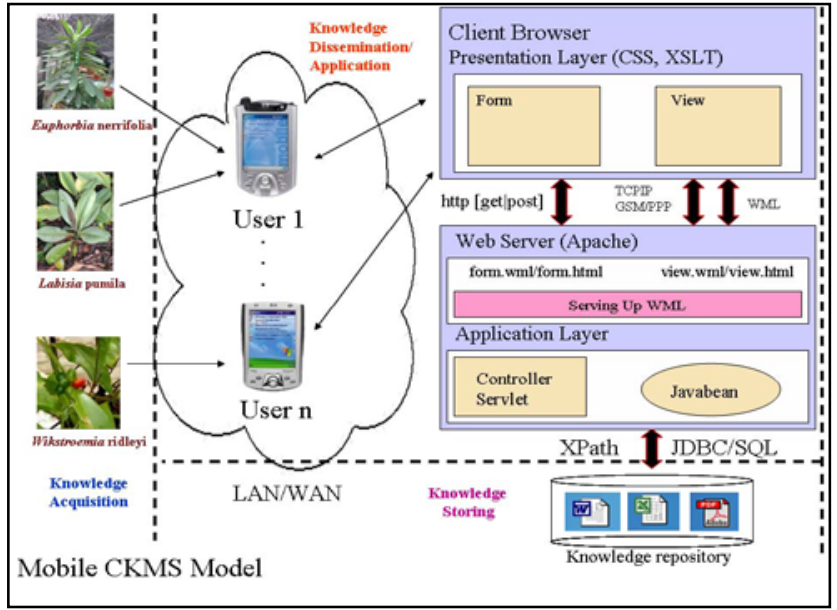

Figure 5. The Integrating Mobile Devices into KMS for Bioinformatics Institutions

\section{Conclusion}

As a conclusion, it seems that Bioinformatics Knowledge Management System could be implemented in the bioinformatics institution with the base of knowledge management framework that has been proposed. In order to develop a successful of KMS, the bioinformatics institution must ensure the proper requirement steps of implementation of $\mathrm{KM}$ system is ready and try to adapt as much as possible of the 
Fahad Omar Alomary; Collaborative Integration of Bioinformatics Knowledge Management System and Mobile Wireless Devices, Transactions on Machine Learning and Artificial Intelligence, Volume 7 No 2 April, (2019); pp: 34-45

technologies that are suitable for. This is needed to ensure that the bioinformatics institutions can gain the benefit from the implementation so that the organizations will not waste the time and money.

The organizations also must have focused on the important of the collaboration environment, whereby the biologists or farmers, academicians, researchers and the administrators can work together, sharing the knowledge and others. Therefore, the organizations also need to find the problem in implementing the knowledge management system in order to make sure that they will always aware of the problem arises and they can try to find the solution to overcome that problem. Here, it is suggested that a proper plan must be adapted along with system implementation in order to maintain the effectiveness of the institution.

\section{REFERENCES}

[1] Wiig, K.M., de Hoog, R., and R. van der Spek. (1997). "Supporting Knowledge Management: A Selection of Methods and Techniques.", Expert Systems with Applications, 13(1).

[2] Morrow, C. and Wilkins, D., (2004), "A Bioinformatics Course in the Computer Science Curriculum", ACM, pp. 192-199.

[3] Satyadas, A., Harigopal, U., and Cassaigne, N. P., (2001), “ Knowledge Management Tutorial: An Editorial Overview," IEEE Transactions on Systems, Man, and Cybernetics-Part C: Applications And Review, vol. 31, no. 4, pp. 429-437.

[4] Wickramasinghe, N. (2002). "Practising What We Preach: Are Knowledge Management Systems in Practice Really Knowledge Management Systems?", Proceedings of the 35th Hawaii International Conference on System Sciences.

[5] Meso, P., \& Smith R., (2000), "View of Organizational Knowledge Management Systems", Journal of Knowledge Management, Vol. 4, No. 3 pg 224-234.

[6] Holsapple, C.W. and Joshi, K.D., (1999). “Description And Analysis of Existing Knowledge Management Framework", Proceedings of 32nd Hawaii International Conference on System Science.

[7] Leonard-Barton, D. (1998). "The Wellsprings of Knowledge: Building and Sustaining the Sources of Innovation", Mass.: Harvard Business School Press.

[8] Andersen, A., and The American Productivity and Quality Center. (1996). The Knowledge Management Assessment Tool: External Benchmarking Version, Winter.

[9] Choo, C.W. (1998b). "Information management for the intelligent organization: The art of scanning the environment", Medford, NJ: Information Today, Inc.

[10] Van der Spek, R. and Spijkervet A. (1997). "Knowledge Management: Dealing Intelligently with Knowledge", Knowledge Management and Its Intergrative Elements, eds (Liebowitz, J. \& Wilcox, L.). New York: CRC Press. 
[11] Szulanski, G. (1996), "Exploring Internal Stickiness: Impediments to the Transfer of Best Practice Within the Firm," Strategic Management Journal (17:Winter Special Issue), pp. 27-43.

[12] Petrash, G. (1996). “Dow's Journey to a Knowledge Value Management Culture”, European Management Journal. Vol. 14, No. 4, pp. 365-373.

[13] Nonaka, I., and Takeuchi, H. (1995). "The knowledge-creating company: How Japanese companies create the dynamics of innovation", New York, Oxford University Press.

[14] Alavi, M. (1997). “KPMG Peat Marwick U.S.: One Giant Brain”, Boston, MA: Harvard Business School.

[15] Kotnour, T. G., Orr, C., Spaulding, J., and Guidi, J. (1997). "Determining the Benefit of Knowledge Management Activities", (Invited Session) IEEE International Conference on Systems, Man and Cybernetics, Orlando, Florida.

[16] Drucker, P. F. (1993). "Post-Capitalist Society", New York: HarperCollins Publishers, Inc.

[17] Rus, I. and Lindvall, M. (2002). “Guest Editors' Introduction: Knowledge Management in Software Engineering", IEEE Software 19(3), 26-38.

[18] Choo, C.W. (1998a). "The knowing organization: How organizations use information to construct meaning, create knowledge, and make decision", New York: Oxford University Press, Inc.

[19] Davenport, T. H., and Prusak, L. (1997). "Working Knowledge: How Organizations Manage What They Know", Cambridge, MA: Harvard Business School Press.

[20] Davenport, T.H., De Long, D.W and Beers, M.C (1998), "Successful knowledge management projects", Sloan Management Review, Winter, pp 43-57.

[21] Myers, S. P. (1996). “Knowledge Management and Organizational Design: An Introduction”, Knowledge Management and Organizational Design. Boston: Butterworth-Heinemann.

[22] Rosemann, M. and Chan, R. (2002). "A Framework to Structure Knowledge for Enterprise Systems". Available at: http://aisel.isworld.org/pdf.asp?Vpath=AMCIS/2000\&PDFpath=260.pdf

[23] Jones, W.T. and Lefkowitz, E.J., (2000). "A Strategy for Initiating Computer Science/Bioinformatics Collaboration", A Lite Bioinformatics Specialization, pp. 20-21. 